\title{
Increased sale of opiates on the blackmarket in the Piccadilly area
}

\begin{abstract}
ANGELA BURR
A recent report by the Advisory Council on the Misuse of Drugs pointed to a recent increase in unethical prescribing and overprescribing of opiates by doctors outside the drug dependency units. ${ }^{1}$ The General Medical Council itself has recognised that such overprescribing is becoming a serious problem and has drawn it to the attention of its standards committee. ${ }^{2}$ The survey by Bewley and Ghodse, which described the views of drug addicts on the overprescribing of these doctors, has provided further evidence. ${ }^{3}$ The case of the general practitioner recently struck off the Medical Register for overprescribing is but one example.
\end{abstract}

\section{Methods}

I conducted a social anthropological study into the Piccadilly black market for pharmaceutical drugs between December 1979 and February 1981 and again in the autumn of $1982 .{ }^{4}$ The Piccadilly drug scene was the first important drug black market in Britain and achieved notoriety in the mid-1960s. Today, as then, it is a major outlet for illicit pharmaceutical drugs-in 1982 for Physeptone (methadone), Diconal (cyclizine hydrochloride and dipipanone hydrochloride), Palfium (dextromoramide), and Ritalin (methylphenidate). Because it plays such an important part in the London pharmaceutical drug subculture, it provides insight into some of the patterns of illicit pharmaceutical opiate use in London. Indeed, this research, which was based on both informal long term observation and the collection of related statistics, provided evidence on the "street" that opiates prescribed by doctors outside drug dependency units are finding their way on to the Piccadilly black market in substantial amounts.

Institute of Psychiatry, Denmark Hill, London SE5 8AF ANGELA BURR, BA, PHD, lecturer and research social anthropologist

\section{Findings}

Fieldwork showed that Piccadilly in the autumn of 1982 was reminiscent of Piccadilly in the mid-1960s, when the London drug black market was flooded with pharmaceutical drugs originating from the overprescribing of a few notorious general practitioners. ${ }^{5}$ The Brain committee was reconvened in 1964 to look into the growing problem of addiction and overprescribing. ${ }^{6}$ As a result of its recommendations, drug dependency units were set up in 1968, and only doctors at these centres were allowed to prescribe heroin and cocaine. Nevertheless, pharmaceutical drugs from various sources, including the drug dependency units, continued to find their way on to the black market and the Piccadilly black market in particular.

This policy change, however, still allowed doctors outside drug dependency units to prescribe synthetic opiates. But few addicts in London had regular daily opiate maintenance prescriptions from doctors outside the clinics until the beginning of the 1980 s, when the number of these prescriptions in the possession of addicts increased sharply. It is a complex subject and difficult to extrapolate cause from effect, but a major reason for this increase appears to have been a change in the treatment practice and prescribing policy of the drug dependency units. By the beginning of the 1980 s waiting lists for first assessment rose to beyond six weeks at many clinics which deterred drug users from going to them. Also, by the mid1970 s, most clinics had changed over to prescribing oral methadone to new patients. Many drug users who had at some time been given injectable maintenance prescriptions but for some reason no longer had them were also treated as "new patients" if they went to a clinic. As the idea became known among unaffiliated drug takers that only non-injectable drugs were available they did not bother going to the clinics. Instead they sought their drug supply elsewhere, particularly those who preferred to inject their drugs. Some bought their drugs on the black market, many in Piccadilly. Others turned to private and National Health Service doctors for injectable synthetic opiates. This change is reflected in the Home Office annual index of opiate notifications. Until the late 1970 s, most Home Office opiate notifications came from doctors in drug dependency units but by 1981 over half came from doctors outside the units. ${ }^{7}$ Of 3592 new and renotifications from England in 1981, 2232 came from the Greater 
London and south east region, ${ }^{1}$ and several hundred of the total 1981 notifications from England came from a few doctors practising near Piccadilly, particularly in the Harley Street area.

\section{First survey}

Piccadilly drug scene: a fixing subculture-Most drugs sold in Piccadilly can be injected and most drug users there, the majority of whom are lower class long term users, prefer to inject. The change in the policy of the drug dependency units was therefore especially felt in Piccadilly. Those drug users who did not have injectable maintenance prescriptions from a drug dependency unit turned to the Piccadilly black market or sought drugs from doctors outside the clinics. Trade in injectable drugs increased, particularly Physeptone and Diconal, and their prices rose dramatically.

Drug users' attitudes to the clinics in 1980-1-In 1980-1, drug users without injectable maintenance prescriptions from a drug dependency unit had an antagonistic attitude to the clinics and many had little to do with them. The ideal at the time, and a source of great prestige, was to get a maintenance prescription from a private doctor, but few seemed to have obtained them. Although there were more, the names of only four private doctors who prescribed maintenance prescriptions to Piccadilly drug users came to light. They were well known in the drug scene as prescribers to addicts. Fear of losing their source of supply made drug users with private prescriptions in 1980-1 secretive about the identities of their doctors. These practitioners generally seemed to prescribe only Physeptone injectable ampoules and mixture. Most drug users sold part of their prescribed supply each week, often in Piccadilly, to pay their doctors' and chemists' fees. One doctor charged $£ 30$ a week, whereas another charged $£ 13$.

\section{Second survey}

By late 1982 conditions in Piccadilly had changed radically. Most drug users who frequented Piccadilly had participated in the scene two years previously. A substantial proportion, however, of those drug users who two years previously had used daily prescriptions or visited Piccadilly frequently but had not had maintenance prescriptions had now obtained them, mostly from private doctors. The names of nine doctors prescribing opiate maintenance prescriptions to Piccadilly drug users came to light, though there were many more. Of these nine, five were new names. Although a substantial proportion of addicts had maintenance prescriptions from doctors in outer London and the provinces, with the exception of one from south London, these nine came from an area within two miles $(3 \mathrm{~km})$ of Harley Street. Their fees seemed to have remained the same. Some of the doctors whose names had been known in 1981 now had far more patients than previously. Among them these nine doctors alone had several hundred patients.

Drug users' attitudes to the drug dependency units and private doctors had also changed. They were no longer antagonistic towards the clinics. Moreover, if their doctors had many addict patients they were more willing to discuss their doctors and to compare and evaluate the relative merits of each. Many drug users seemed to be under the impression that the willingness of the Home Office to allow these doctors to prescribe to them indicated that the Home Office was on their side and was trying to provide for their needs.

Before getting these prescriptions many drug users had obtained their drugs by theft from chemists, pharmaceutical factories, or surgeries; from fraudulent prescriptions; or from ad hoc prescriptions from doctors. Now that they had regular prescriptions from doctors outside the clinics some, although still involved in crime with the exclusion of dealing, appeared to be less involved in directly drug related criminal activities.

The prescribing practices of the doctors had also altered radically by 1982 . Some were now also prescribing Diconal, Palfium, and Ritalin. One or two of them seemed to be prescribing to addicts who were in a poor physical condition and unsuitable for injectable drugs. One long term addict was prescribed 30 Ritalin and 30 Diconal pills a week, which had a black market value of $£ 180$, yet his veins had long since collapsed and he was in a poor shape. Actually, he used to sell a proportion of his prescription.

Several of the medical practitioners appeared to be prescribing larger than necessa:y doses. These doctors do not have access to the FP $10 \mathrm{HP}(\mathrm{AD})$ prescription pads that allow doctors to prescribe a whole fortnight's daily dispensed opiate on one slip. Currently, to provide daily dispensing, doctors outside clinics have to write a separate prescription for each day, something that they are generally unwilling to do. As a result they often prescribe very large doses to be dispensed at one time. Supplying addicts with more than their daily need provides them with surplus drugs, which many of them soon sell even though they may later need them themselves. This has also resulted in some drug users using more than their allotted daily dose at any one time, and in consequence their tolerance level has increased.

Most drug users with maintenance prescriptions from doctors outside drug dependency units sold part of their prescriptions, for similar reasons as before. Most did not seem to need the total amount, and they sold a proportion of their prescription to buy other drugs which they preferred.

A change was also noticeable in the repertoire of drugs on sale in Piccadilly in late 1982. Previously, barbiturates, which were easily obtainable, were one of the main drugs on sale. Fewer barbiturates in general are now being prescribed but this alone does not account for their pronounced absence from the drug scene in 1982. Barbiturates appear to have been supplanted by pharmaceutical opiates because the latter are so easy to get and are more profitable to sell.

Moreover, Diconal, which some of these medical practitioners were now prescribing on maintenance prescriptions, had become as common as Physeptone and more sought after. The increase in the overspill of pharmaceutical opiates had brought down the price of drugs, particularly Physeptone. Ten milligram injectable Physeptone ampoules that had cost $£ 5-6$ each in 1981 were now $£ 4-5$. Drug users attributed this fall in price to overprescribing by doctors outside drug dependency units.

Some of the drug users took their maintenance prescriptions prescribed by general and private practitioners to several chemists in London known to accept prescriptions from drug addicts. One is in Shaftesbury Avenue. The most important fact noted in late 1982 was that the Piccadilly drug scene had changed its venue. In 1980 most dealing had taken place in and around subway four in the underground station. In 1981 the scene moved to the Upper Haymarket. But in mid-1982 it moved once again, to the area around Halls chemist shop in Shaftesbury Avenue.

Since the scene moved to his chemist shop, according to the proprietor, interviewed in January 1983, he has on average 300 visits a day from drug users, though often some of these visits are from the same person. Nowadays, up to 20 drug users at a time at peak dealing hours are to be seen congregating around the shop. Often when they come out having either picked up prescriptions or bought hypodermics and needles, or both, they negotiate deals with buyers in front of the shop. Some even hand over the drugs there and then. The situation outside the Shaftesbury Avenue chemists is now similar to that in Piccadilly Circus in the mid-1960s.

Some drug users maintain that the scene shifted because they were hassled too much by the police in the Haymarket. Another cause too may have been that a private doctor prescribing large quantities of Diconal had set up in practice nearby. But an important reason was perhaps the increase in the number of Piccadilly addicts with prescriptions from private and NHS doctors and the type of addict who had obtained them. According to the proprietor, this chemist, since the 1960s, had always dispensed a sizable proportion of prescriptions from drug dependency units, but in mid-1982 there had been a boom in prescriptions from doctors outside the clinics, particularly private doctors. He estimated that in the mid-summer of 1982, at about the time that the scene moved to the Haymarket, he was being presented each week with some 50-60 opiate maintenance prescriptions, mostly from private doctors, and perhaps a similar amount of ad hoc prescriptions as well as about five maintenance prescriptions from the clinics. The names of the doctors prescribing the regular prescriptions dispensed by this chemist in mid-1982 were mainly the same one from the south and central London areas who had become well known as drug addict doctors in the Piccadilly drug scene.

That the Piccadilly drug scene moved to the area around this chemist shop at a time when many opiate prescriptions were being dispensed there would appear to be directly associated. Those drug users who had obtained prescriptions from doctors outside drug dependency units in the past two years, often tended to have been regular, often daily, visitors to Piccadilly for long periods. Before obtaining medical practitioner prescriptions to support their habits, they had often acted as dealers or runners in drugs obtained from other sources. Some were the backbone of the dealing and running system in Piccadilly. It was a few of these who precipitated the move to Shaftesbury Avenue. When they obtained their maintenance prescriptions, a number of them, including a group of the most influential dealers and runners, dealt directly from the neighbourhood of the chemist shop itself. Because of their focal position in the drug 
market, the rest of the scene gradually moved with them including the substantial proportion of drug users who preferred obtaining their prescriptions from less conspicuous chemist shops. Although the chemist proprietor reported in 1983 that the number of addict maintenance prescriptions he dispensed halved in the second half of 1982, after the publicity over Dr Khan's case, the thriving market in pharmaceutical drugs from the overspill from doctors outside drug dependency units continued to focus around this chemist shop even though most drug users obtained their drugs from chemist shops elsewhere. Such a shop was, of course, the natural focus for a scene that was becoming a major outlet for legitimately obtained prescriptions.

\section{Conclusion}

Although fieldwork in late 1982 was based on informal observation alone, opinions were also obtained from a substantial number of addicts well known to me and there was a general consensus among them on the subject of overprescribing by doctors outside drug dependency units. This, and my knowledge of the scene, suggest that an important change has occurred in Piccadilly. This is corroborated by the recent article on overprescribing doctors by Bewley and Ghodse. ${ }^{3}$

The focal part Piccadilly plays in the London pharmaceutical drug black market and the relatively small number of doctors outside drug dependency units who prescribe for addicts must be taken into account when evaluating the opiate overspill in Piccadilly. Not all doctors from Harley Street and the sur- rounding area or doctors outside drug dependency units in general are injudiciously overprescribing to addicts. Nevertheless, it would seem reasonable to conclude from the substantial amount of pharmaceutical opiates appearing on the black market in Piccadilly prescribed by doctors outside the clinics, that a considerable proportion of opiates prescribed by medical practitioners from Greater London, the Home Counties, and the Harley Street and surrounding area in particular, is finding its way on to the black market in Piccadilly. As such, the situation gives cause for concern and would appear to need urgent attention.

\section{References}

${ }^{1}$ Department of Health and Social Security. Treatment and rehabilitation: report of the Advisory Council on the Misuse of Drugs. London: HMSO, 1982.

${ }^{2}$ General Medical Council. General Medical Council annual report for 1981. London: GMC, 1981:15.

${ }^{3}$ Bewley T, Ghodse H. Unacceptable face of private practice: prescription of controlled drugs to addicts. $\mathrm{Br}$ Med $\mathcal{F} 1983 ; \mathbf{2 8 6}: 1876-1977$.

${ }^{4}$ Burr AMR. The Piccadilly drug scene. Br f Addict 1983;178:5-19.

${ }^{5}$ Edwards G, Busch C, eds. Drug problems in Britain: review of ten years. London: Academic Press, 1981.

${ }^{6}$ Interdepartmental Committee. Drug addiction: the second report of the interdepartmental committee. London: HMSO, 1965.

${ }^{7}$ Mayhew P. House of Commons Official Report (Hansard). 1982;March 18: $1236,174-5$.

(Accepted 12 fuly 1983)

\title{
For Debate...
}

\section{Do we need hypertensionologists?}

\author{
D G BEEVERS
}

Hypertension is far and away the commonest medical condition that requires drug treatment. It is the most important single treatable risk factor for both coronary heart disease and stroke, which, combined, kill more people than all other causes. Despite this there are few specialists in British hospitals who list hypertension as their main interest. In the past hypertension specialists tended to be highly academic scientists, concerned mainly with the blood pressure of rats rather than humans. No fewer than four London professors of medicine were primary hypertensionologists. It is a pity, however, that this number has declined at a time when the treatment of hypertension is becoming more complex and more important. In most district hospitals patients with hypertension are looked after by general physicians, who are primarily concerned with other diseases. Occasionally, cardiologists, nephrologists, and even endocrinologists take a hand. Inevitably, patient care tends to be somewhat unsystematic.' In general, cardiologists have not chosen to adopt hypertension as "their disease." It is notable that Professor J R

University Department of Medicine, Dudley Road Hospital, Birmingham B18 7QH

D G BEEVERS, MD, FRCP, senior lecturer in medicine
Hampton did not mention high blood pressure and its treatment in his article on the future of cardiovascular medicine. ${ }^{2}$

The disparity between the prevalence of the disease and the number of specialists devoted to it suggests that action is needed to create a new specialty. Interest in hypertension is expanding across the world. In the United States of America many university centres and large hospitals now have independent divisions of hypertension or hypertension research centres. Many countries now also have national high blood pressure societies, and, not before time, the British Hypertension Society has been formed. In addition, there is the enormous International Society of Hypertension, and recently a major meeting was held in Milan of European hypertension workers that attracted about 1200 delegates. These organisations and meetings reflect the wide range of specialists, who approach hypertension from differing points of view. Sadly, few general practitioners are active participants, although those that are contribute a great deal.

\section{General practitioner hypertensionologists}

Most patients with hypertension need little investigation, and adequate blood pressure control can be achieved by simple means. Few patients need to be referred to hospital. In Britain, 